\title{
A simple method to estimate renal volume from computed tomography
}

\author{
Rodney H. Breau, MSc MD, FRCSC;, Edward Clark, MD, ; Bryan Bruner, MD; ${ }^{*}$ Patrick Cervini, MD; ${ }^{*}$ Thomas \\ Atwell, MD;* Greg Knoll, MD; ${ }^{*}$ Bradley C. Leibovich, MD
}

${ }^{\star}$ Ottawa Hospital Research Institute, Ottawa, ON; †Division of Urology, University of Ottawa, Ottawa ON; §Division of Nephrology, University of Ottawa ON; †Department of Urology, Mayo Clinic, Rochester MN; *Department of Radiology, Mayo Clinic, Rochester MN

See related article on page 193.

Cite as: Can Urol Assoc J 2013;7(5-6):189-92. http://dx.doi.org/10.5489/cuaj.1338

\section{Abstract}

Introduction: Renal parenchymal volume can be used clinically to estimate differential renal function. Unfortunately, conventional methods to determine renal volume from computed tomography (CT) are time-consuming or difficult due to software limitations. We evaluated the accuracy of simple renal measurements to estimate renal volume as compared with estimates made using specialized CT volumetric software.

Methods: We reviewed 28 patients with contrast-enhanced abdominal CT. Using a standardized technique, one urologist and one urology resident independently measured renal length, lateral diameter and anterior-posterior diameter. Using the ellipsoid method, the products of the linear measurements were compared to $3 \mathrm{D}$ volume measurements made by a radiologist using specialized volumetric software.

Results: Linear kidney measurements were highly consistent between the urologist and the urology resident (intraclass correlation coefficients: 0.97 for length, 0.96 for lateral diameter, and 0.90 for anterior-posterior diameter). Average renal volume was 170 (SD: 36) $\mathrm{cm}^{3}$ using the ellipsoid method compared with 186 (SD 37) $\mathrm{cm}^{3}$ using volumetric software, for a mean absolute bias of -15.2 (SD 15.0) $\mathrm{cm}^{3}$ and a relative volume bias of $-8.2 \%(p<0.001)$. Thirty-one of 56 (55.3\%) estimated volumes were within $10 \%$ of the 3D measured volume and 54 of 56 (96.4\%) were within $30 \%$. Conclusion: Renal volume can be easily approximated from contrast-enhanced CT scans using the ellipsoid method. These findings may obviate the need for 3D volumetric software analysis in certain cases. Prospective validation is warranted.

\section{Introduction}

The use of computed tomography (CT) for preoperative assessment of the renal anatomy is common. ${ }^{1-3}$ In addition, renal volume estimated by $\mathrm{CT}$ also correlates with renal function $^{4-11}$ and permits concurrent evaluation of differential renal function. ${ }^{12-16}$ Unfortunately, renal volume estimates using $\mathrm{CT}$ are time-consuming or require specialized 3D volumetric software, ${ }^{12,13,15,17,18}$ which has rarely been made available for use in comparative studies. ${ }^{18}$

Multiple previous studies have used a simple method to estimate renal volume that substitutes linear renal dimensions from 2D ultrasound, magnetic resonance imaging (MRI) or CT scans into a formula for calculating the volume of an ellipsoid. ${ }^{18-23}$ The largest study to use the ellipsoid method of renal volume estimation with CT evaluated 1018 patients after radical or partial nephrectomy and incorporated the estimated renal volume into a prognostic nomogram for postoperative renal insufficiency. ${ }^{19}$ The nomogram was found to be predictive of the 7-year probability of renal failure $(r=0.84)$, but was not specifically designed to determine the accuracy of the ellipsoid method for estimating renal volume. ${ }^{19}$ While early studies using ultrasound and MRI demonstrated that the ellipsoid method is likely to underestimate renal volume and can suffer from poor inter-observer reliability, ${ }^{24-26}$ less was known about the accuracy of the ellipsoid method when CT measurements were used. ${ }^{18,23}$ In 2011, Hwang and colleagues reported on the accuracy of contrast $\mathrm{CT}$ measurements to estimate renal volume in 138 living kidney donors. ${ }^{23}$ The gold standard was a volume calculated using kidney measurements taken using calipers following nephrectomy. The correlation coefficient for the ellipsoid method $(r=0.72)$ was slightly less than that for the voxel-count method $(r=0.79)$, in which the sum of the area of each CT slice image is multiplied by the thickness of each section using automated software.

More recently, a study reported the accuracy of contrast CT-based estimates of split renal function for 38 potential renal donors with a modified ellipsoid method using nuclear renography as the gold standard. ${ }^{18}$ The authors concluded that, using measurements taken by radiologists, the ellipsoid method could obviate the need for nuclear renography in many such patients given the "high accuracy" $(r=0.84)$ and "limited time for post-processing." 18 
Breau et al.

The purpose of this study was to determine how well simple contrast CT-based renal volume estimates made by urologists using the ellipsoid method compare with those determined using specialized 3D volumetric software.

\section{Methods}

A convenience sample of 28 consecutive patients was included in the study. All patients were evaluated at a single institution with a contrast-enhanced abdominal CT scan. Patients included in the study had kidneys without congenital, cystic or neoplastic abnormalities. Preoperative renal function was estimated using the 4-variable Modification of Diet in Renal Disease (MDRD) formula. ${ }^{27}$ Before starting the study, we received approval from the Mayo Clinic Institutional Review Board. Given that no intervention was involved and the CT scans of patients included in the study were done as part of routine care, the requirement for patient consent was waived.

\section{Estimated renal volume from 2D kidney measurements}

Linear renal dimensions (length, lateral diameter, anteriorposterior diameter) were measured independently by a urology resident and a urologist. Each reviewer was blinded to the other reviewer's measurements and to the 3D volume measurements. Renal length was calculated from axial slices by multiplying the slice thickness by the number of slices between the superior and inferior tips of the kidneys. The slice represented the greatest cross-sectional area for width and thickness measurements. Lateral diameter was measured from the lateral extent of the kidney to the renal sinus and anterior-posterior diameter was measured perpendicular to the lateral diameter (Fig. 1).

\section{Renal volume using 3D software}

The radiologist was blinded to the measurements collected by the urologist and urology resident. Renal volumes were calculated based on volume measuring software available on an Advantage Workstation (General Electric, Milwaukee, WI). Axial CT images acquired at 5-mm slice thickness were electronically transferred to the imaging workstation. The renal cortex was traced on each image showing renal parenchyma and the renal pelvis was excluded from volume measurement. Following complete tracing of each kidney, CT volume was automatically calculated.

\section{Data analysis}

Renal volume was estimated from the linear dimensions using the ellipsoid formula (Table 1). Agreement in linear renal dimensions and volume were assessed using intraclass correlation coefficients (ICC). The paired T-test was used to compare 3D software volumes to ellipsoid equation estimated volumes. Absolute volume bias was calculated by subtracting the estimated renal volume from the $3 \mathrm{D}$ renal volume. Relative volume bias was calculated by dividing the absolute volume bias by the 3D renal volume. Accuracy was determined by the proportion of cases where the relative volume bias was within $10 \%$ or $30 \%$ of the $3 \mathrm{D}$ volume.

\section{Results}

We tallied baseline patient characteristics (Table 2). Linear measurements were consistent between observers with intraclass correlation coefficients of $0.97,0.96$ and 0.90 for length, lateral diameter, and anterior-posterior diameter, respectively. Volume estimates based on the ellipsoid equation were highly consistent between reviewers $(r=0.95)$ (Fig. 1).

There was good agreement between estimated volumes calculated using the ellipsoid equation with those measured using the 3D volumetric software (ICC 0.83 for reviewer 1 and 0.75 for reviewer 2) (Fig. 2). Average renal volume was $170 \mathrm{~cm}^{3}$ (SD 36) using the ellipsoid method compared with $186 \mathrm{~cm}^{3}$ (SD 37) using volumetric software, for a mean absolute bias of $--15.2 \mathrm{~cm}^{3}$ (SD 15.0) and a relative volume bias was $-8.2 \%(p<0.001)$. Thirty-one of $56(55.3 \%)$ estimated volumes were within $10 \%$ of the $3 \mathrm{D}$ measured volume and 54 of $56(96.4 \%)$ were within $30 \%$.

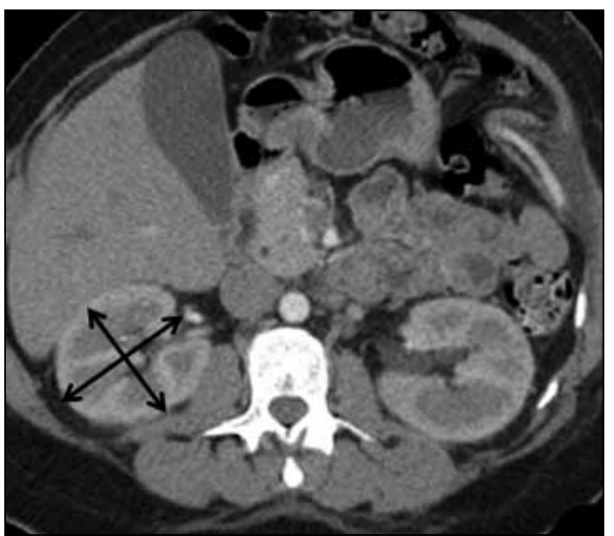

Fig. 1. Axial renal image with lateral diameter measured from the lateral extent of the kidney to the renal sinus and perpendicular anterior-posterior diameter.

Table 1. The ellipsoid formula volume to estimate renal volume

length $x$

lateral diameter $x$

anterior-posterior diameter $x$

$\pi / 6$ 


\begin{tabular}{|c|c|c|}
\hline \multicolumn{2}{|l|}{ Characteristic } & Mean \pm SD (Median; range) \\
\hline \multicolumn{2}{|l|}{ Age (years) } & $57.3 \pm 15.7(61.5 ; 19-77)$ \\
\hline \multicolumn{2}{|l|}{ Height* $(\mathrm{cm})$} & $171.3 \pm 11.4(170 ; 154-196)$ \\
\hline \multicolumn{2}{|l|}{ Weight* (kg) } & $87.9 \pm 21.3(87 ; 54-133)$ \\
\hline \multicolumn{2}{|l|}{$\mathrm{BMI}^{*}\left(\mathrm{~kg} / \mathrm{m}^{2}\right)$} & $29.9 \pm 6.4(29.1 ; 19.2-42.5)$ \\
\hline \multirow{2}{*}{\multicolumn{2}{|c|}{$\begin{array}{l}\text { Preoperative } \mathrm{GFR}^{\S *}(\mathrm{~mL} / \mathrm{min} / 1.73 \\
\left.\mathrm{m}^{2}\right)\end{array}$}} & $67.6 \pm 13.1(71.0 ; 29.0-85.8)$ \\
\hline & & $\mathrm{n}(\%)$ \\
\hline \multicolumn{2}{|l|}{ Female gender } & $14(50)$ \\
\hline \multirow[t]{2}{*}{ Side of assessment } & Left & $16(57)$ \\
\hline & Right & $12(43)$ \\
\hline
\end{tabular}

\section{Discussion}

We found this easy-to-perform ellipsoid method of estimating renal volume consistent between non-radiologist observers. We also found the estimated volumes correlated closely to measurements made using specialized 3D volumetric software. On average, the ellipsoid method slightly underestimated $3 \mathrm{D}$ volumes, but almost all were accurate within $30 \%$. Given the established relationship between renal volume and function, ${ }^{4-16}$ our findings suggest $3 \mathrm{D}$ volume software analysis is not necessary when estimating differential renal function.

Older studies using 2D measurements from ultrasound or MRIs revealed poor intra-observer reliability and, in general, a larger underestimate of renal volume. ${ }^{24-26}$ In this study using CT images, we found good intra-observer reliability, lower bias and good accuracy. These findings are consistent with recent publications; estimated renal volume using an ellipsoid equation with $\mathrm{CT}$ measurements, performed by radiologists, was highly correlated to renal scan differential function $(r=0.84)$ in one study ${ }^{18}$ and volume directly calculated using direct post-nephrectomy measurements in another. ${ }^{23}$

Using the ellipsoid equation to estimate renal volume from CT images is faster than most 3D imaging software. In a study of radiologists, the 2D measurements took an average of 53 seconds compared to 302 seconds for semiautomated 3D software ${ }^{10}$ and other studies report that about 15 minutes of post-processing is required for $3 \mathrm{D}$ volume software without automation. ${ }^{15,28}$

A potential pitfall to using renal volume to estimate renal function is that these measurements do not include functional assessment, such as contrast attenuation. It would seem logical that information about filtration function would add to the assessment of differential function. However, several studies show that calculations incorporating volume and attenuation are less correlated to renal function than renal volume alone. ${ }^{12-15,18}$

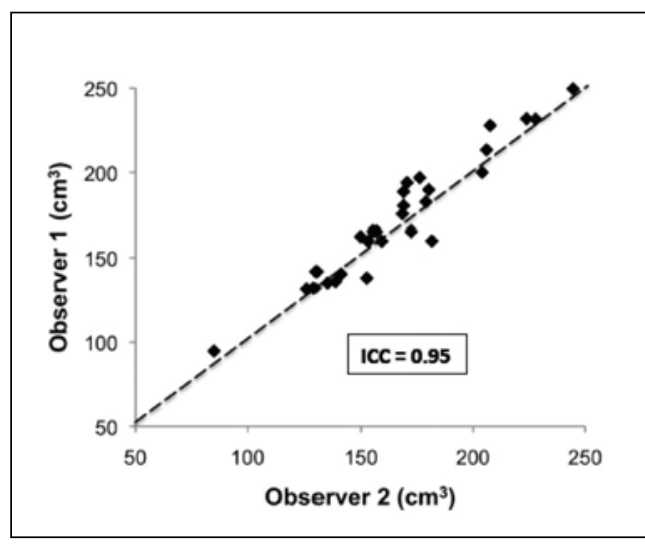

Fig. 2. Scatterplot of calculated renal volumes using 2-dimentional lengths and the ellipsoid equation from observer 1 and 2.

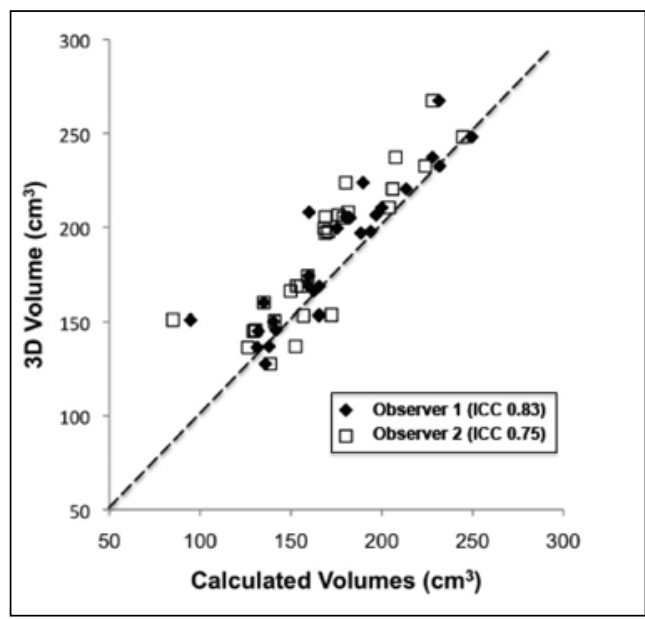

Fig. 3. Scatterplot of calculated renal volumes from observer 1 and 2 compared to software generated 3-dimentional volumes.

There are several important limitations to our study. Patients did not have renal tumours and did not have major anatomic or perfusion differences (i.e., large renal cyst, hydronephrosis, segmental infarctions). As a recent study by Gabitey and colleagues demonstrated, volumetric analysis using 3D software for CT scan-based parenchymal kidney volume measurements may be useful in the "prediction of renal mass preservation and renal function in the arena of nephron-sparing surgery. ${ }^{\prime 29}$ Given that the ellipsoid method may not account for structural renal abnormalities, it may not be clinically useful in these patients. Our findings do, however, support the use of ellipsoid-based volume estimates to assess split renal function for prospective transplant kidney donors given that such patients are likely to have renal abnormalities only as incidental findings. In addition, several studies have reported an association between transplant kidney volume estimated using CT and long-term recipient renal function. ${ }^{6,30,31}$ Further studies in this field 
might be facilitated by the routine implementation of the ellipsoid technique for renal volume estimation, one that is relatively easily added to the routine clinical workflow of radiologists or urologists. ${ }^{18}$ Lastly, having used a convenience sample of relatively few patients, only 2 reviewers, and 1 type of specialized 3D volumetric software, future studies involving more patients and reviewers are required to validate our findings.

\section{Conclusion}

We found that in using contrast-enhanced CT, a simple method to estimate renal volume, we were able to show good intra-observer reliability and performed well compared to $3 \mathrm{D}$ software-based measurements. This suggests that the use of specialized 3D software to estimate kidney volume may be of limited additional value in the preoperative assessment of differential renal function in certain circumstances.

Competing interests: None declared.

This paper has been peer-reviewed.

\section{References}

1. Kawamoto S, Montgomery RA, Lawler LP, et al. Multidetector CT angiography for preoperative evaluation of living laparoscopic kidney donors. AJR Am J Roentgenol 2003;180:1633-8. http://dx.doi. org/10.2214/air.180.6.1801633

2. Kim JK, Park SY, Kim HJ, et al. Living donor kidneys: usefulness of multi-detector row CT for comprehensive evaluation. Radiology 2003;229:869-76. http://dx.doi.org/10.1148/radiol.2293021098

3. Raman SS, Poichamarnwiputh S, Muangsomboon K, et al. Utility of 16-MDCT angiography for comprehensive preoperative vascular evaluation of laparoscopic renal donors. AJR Am J Roentgenol 2006; 186:16308. http://dx.doi.org/10.2214/AJR.05.0983

4. Tsushima Y, Blomley M, Kusano S. Use of contrast-enhanced computed tomography to measure clearance per unit renal volume: a novel measurement of renal function and fractional vascular volume. Am I Kidney Dis 1999;33:754-60. http://dx.doi.org/10.1016/S0272-6386(99)70230-1

5. Tanaka $N$, Fujimoto $\mathrm{K}$, Tani $M$, et al. Prediction of postoperative renal function by preoperative serum creatinine level and three-dimensional diagnostic image reconstruction in patients with renal cell carcinoma. Urology 2004;64:904-8. http://dx.doi.org/10.1016/j.urology.2004.07.006

6. Saxena $A B$, Busque $S$, Ariane $P$, et al. Preoperative renal volumes as a predictor of graft function in living donor transplantation. Am J Kidney Dis 2004:44:877-85.

7. Kotre $[J$, Owen JP. Method for the evaluation of renal parenchymal volume by X-ray computed tomography. Med Biol Eng Comput 1994;32:338-41. http://dx.doi.org/10.1007/BF02512534

8. Gong I, Hwang J, Choi D, et al. Relationship among total kidney volume, renal function and age. J Urol 2012;187:344-9. http://dx.doi.org/10.1016/i.juro.2011.09.005

9. Gandy SJ, Armoogum K, Nicholas RS, et al. A clinical MRI investigation of the relationship between kidney volume measurements and renal function in patients with renovascular disease. Br J Radiol 2006;80:1220. http://dx.doi.org/10.1259/bir/11148990

10. D'Souza RC, Kotre CJ, Owen JP, et al. Computed tomography evaluation of renal parenchymal volume In patients with chronic pyelonephritis and its relationship to glomerular filtration rate. $\mathrm{Br} J$ Radiol 1995;68:130-3. http://dx.doi.org/10.1259/0007-1285-68-806-130
11. Blomley MJK, Dawson P. The quantification of renal function with enhanced computed tomography. Br J Radiol 1996;69:989-95. htrp://dx.doi.org/10.1259/0007-1285-69-827-989

12. Summerlin AL, Lockhart ME, Strang AM, et al. Determination of split renal function by $3 D$ reconstruction of CT angiograms: a comparison with gamma camera renography. AJR Am J Roentgenol 2008; 191:1552-8. http://dx.doi.org/10.2214/AJR.07.4023

13. Kato F, Kamishima T, Morita K, et al. Rapid estimation of split renal function in kidney donors using software developed for computed tomographic renal volumetry. Eur J Radiol 2011;79:15-20. http:// dx.doi.org/10.1016/i.eirad.2009.11.013

14. Miyazaki C, Harada H, Shuke N, et al. (99m)TC-DTPA dynamic SPECT and CT volumetry for measuring split renal function in live kidney donors. Ann Nucl Med 2010;24:189-95. http://dx.doi.org/10.1007/ s12149-010-0349-y

15. Morrisroe SN, Su RR, Bae KT, et al. Differential renal function estimation using computed tomography based renal parenchymal volume measurement. J Urol 2010;183:2289-93. http://dx.doi.org/10.1016/i. juro.2010.02.024

16. Nilsson $\mathrm{H}$, Wadström J, Andersson LG, et al. Measuring split renal function in renal donors: can computed tomography replace renography? Acta Radiol 2004;45:474-80. http://dx.doi. org $/ 10.1080 / 02841850410005282$

17. Jeon HG, Gong IH, Hwang JH, et al. Prognostic significance of preoperative kidney volume for predicting renal function in renal cell carcinoma patients receiving a radical or partial nephrectomy. BJU Int 2012;109:1468-73. http://dx.doi.org/10.1111/j.1464-410X.2011.10531.x

18. Soga S, Briz-Cunningham S, Kumamaru KK, et al. Comprehensive comparative study of computed tomography-based estimates of split renal function for potential renal donors: modified ellipsoid method and other CT-based methods. J Comput Assist Tomogr 2012;36:323-9. http://dx.doi.org/10.1097/ RCT.0b013e318251db15

19. Sorbellini M, Kattan MW, Snyder ME, et al. Prognostic normogram for radical or partial nephrectomy. J Urol 2006;176:472-6. http://dx.doi.org/10.1016/i.juro.2006.03.090

20. Geraghty EM, Boone JM, McGahan JP, et al. Normal organ volume assessment from abdominal CT. Abdom Imaging 2004;29:482-90. http://dx.doi.org/10.1007/s00261-003-0139-2

21. Jones TB, Riddick LR, Harpen MD, et al. Ultrasonographic determination of renal mass and renal volume. J Ultrasound Med 1983;2:151-4.

22. Moorthy HR, Venugopal P. Measurement of renal dimensions in vivo: A critical appraisal. Indian I Urol 2011;27:169-75. http://dx.doi.org/10.4103/0970-1591.82832

23. Hwang HS, Yoon HE, Park JH, et al. Noninvasive and direct measures of kidney size in kidney donors. Am J Kidney Dis 2011;58:266-71. http://dx.doi.org/10.1053/i.ajkd.2011.02.392

24. Bakker J, Olre $M$, Kaatee $R$, et al. In vitro measurement of kidney size: comparison of ultrasonography and MRI. Ultrasound Med Biol 1998;24:683-8. http://dx.doi.org/10.1016/S0301-5629(97)00212-3

25. Bakker J, Olree $M$, Kaatee $R$, et al. Renal volume measurements: accuracy and repeatability of US compared with that of MR imaging. Radiology 1999;211:623-8.

26. Cheong $B$, Uthupillai $R$, Rubin MF, et al. Normal values for renal length and volume as measured by magnetic resonance imaging. Clinical Journal Am Soc Nephrol 2007;2:38-45. http://dx.doi.org/10.2215/ CJN.00930306

27. Levey AS, Greene T, Kusek J, et al. A simplified equation to predict glomerular filtration rate from serum creatinine. J Am Soc Nephrol 2000;11:155A.

28. Kim HC, Yang DM Jin W, et al. Relation between total renal volume and renal function: usefulness of $3 D$ sonographic measurements with a matrix array transducer. AJR Am J Roentgenol 2010;194:W186-92. http://dx.doi.org/10.2214/AJR.09.3106

29. Gorbatiy V, Iremashvili V, Castro A, et al. Renal Volumetric Analysis: A New Paradigm in Renal Mass Treatment Assessment. J Endourol 2012;27:361-5. http://dx.doi.org/10.1089/end.2012.0195

30. Yano $M$, Lin MF, Hoffman KA, et al. Renal measurements on CT angiograms: correlation with graft function at living donor renal transplantation. Radiology 2012;265:151-7. http://dx.doi.org/10.1148/ radiol. 12112338

31. Hugen CM, Polcari AJ, Faroog AV, et al. Size does matter: donor renal volume predicts recipient function following live donor renal transplantation. J Urol 2011;185:605-9. http://dx.doi.org/10.1016/i. juro.2010.09.098

Correspondence: Dr. Rodney H. Breau, Department of Surgery, Division of Urology, The Ottawa Hospital, General Campus, 501 Smyth Rd, Box 222, Ottawa, ON, K1H 8L6; fax: 613-737-3019; rbreau@toh.on.ca 